\section{Concurrence of Left Maxillary Antrolith and Right-Sided Nasal Inverted Papilloma: Case Report}

\section{Journal of}

Clinical \& Medical Case Reports

\begin{abstract}
Mehmet Karataş ${ }^{1 *}$, Yasin Sarıkaya ${ }^{1}$, Sedat Doğan ${ }^{1}$, Cem Bayraktar ${ }^{1}$, Emin Kaskalan ${ }^{1}$ and Hacı Mehmet İnan ${ }^{2}$
\end{abstract}

${ }^{1}$ Adiyaman University Medical School, Department of Otorhinolaryngology, Adlyaman, Turkey

${ }^{2}$ Adiyaman University Medical School, Department of Pathology, Adiyaman, Turkey

\begin{abstract}
Antroliths are calcified masses within the maxillary sinus and are detected incidentally on radiological examinations. They occur as a result of the solidification of mucus and nasal debris by mineral salts, calcium, magnesium phosphate and carbonate. The origin of the nidus of calcification may be extrinsic (foreign body in sinus) or intrinsic (stagnant mucus and fungal ball). Inverted papilloma (IP) is the most common benign tumor of the nose and the paranasal sinuses and comprises almost $0.5 \%$ to $4 \%$ of the primary nasal tumors. Herein we present a case of a 65 -years old woman with complaints of rightsided nasal obstruction, epistaxis, and headache for the last 6 months, report the concurrence of left maxillary antrolith and right-sided nasal inverted papilloma which is the first case report in the literature and discuss the pathophysiologies of these two entities in the light of the literature.
\end{abstract}

\section{Introduction}

Inverted papilloma (IP) or inverted type of Schneiderian papilloma is a benign, locally aggressive nasal lesion with a tendency for local recurrence. IP was described first by Ward and Billroth in 1854 and later characterized histologically by Ringert in 1938 [1,2]. It comprises $0.5-4 \%$ of all nasal tumours and is associated with a sinonasal carcinoma in $5 \%$ of patients [3]. In contrast with nasal inflammatory polyp, IP has historically been considered as a true neoplasm [4]. It was suggested that IP is the terminal stage of chronic inflammatory process rather than a real neoplasm [5]. Microscopically, IP shows digitiform proliferation of squamous epithelium into the underlying stroma [3]. Unlike most papillomas of the body, IP inverts, rather than everts, into the underlying connective tissue stroma [2].

Antrolith (AL) is a calcified mass in maxillary sinus. Maxillary sinus stones are uncommon and their development is similar to that of a sialolith. They have been described in various names as antral rhinoliths, antral calculi, antroliths, sinoliths and antrorhinoliths. ALs may form around a nidus or a concentrated mucus, which continues to grow because of the precipitation of calcium salts in concentric layers [6,7]. Smaller ALs are usually asymptomatic and found incidentally on radiographic imaging [8].

MRI and CT, the most commonly used imaging modalities in paranasal sinus evaluation, may incidentally detect the pathologies other than the patient complains about. Herein, we present a case of a 65 -years old woman with complaints of right-sided nasal obstruction, epistaxis, and headache for the last 6 months, report the concurrence of left maxillary antrolith and right-sided nasal inverted papilloma which is the first case report in the literature and try to discuss the pathophysiologies of these two entities in the light of the literature.

\section{*Address for Correspondence:}

Mehmet Karataş, Assistant Professor, Department of Otorhinolaryngology, Faculty of Medicine, Adıyaman University, Adıyaman, Turkey, Tel: +9 0532 7048441; E-mail: mehmetkaratas78@gmail.com.tr

Submission: 09 March 2015

Accepted: 17 March 2015

Published: 21 March 2015

Reviewed \& Approved by: Dr. Runjan Chetty, Deputy Medical Director, Laboratory Medicine Program, University Health Network, Canada

\section{Case Report}

A 65-years old woman with complaints of right-sided nasal obstruction, epistaxis, and headache for the last 6 months presented to our clinic. Nasal endoscopy showed irregular, polypoid mass in right ostiomeatal region and moderate deviation of the nasal septum convexity to the left. Paranasal sinus CT revealed an irregular, polypoid, hypodense mass composed of right antral and choanal parts, and an irregular, $1 \times 2 \mathrm{~cm}$ in size, left antral hyperdense lesion with surrounding hypodense area (Figure 1).

Endoscopic sinus surgery revealed that right ethmoid and maxillary sinuses are fulfilled with an irregular polypoid mass (Figure 2). Histopathologic examination of the soft tissue revealed that epithelial proliferation which grows down into preexisting mucosal glands, displacing and replacing normal epithelium, characteristic findings of inverted papilloma, and this spesific fungiform pattern is caused by the invagination of mucosal epithelium into the underlying

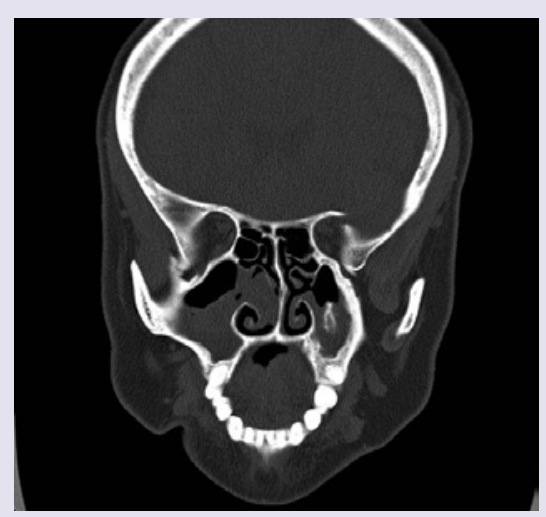

Figure 1: Coronal paranasal sinus $\mathrm{CT}$ reveals hypodense lesion in right nasa cavity originating possibly from right maxillary sinus and irregular, hyperdense lesion in left maxillary sinus. 
Citation: Karataş M, Sarıkaya Y, Doğan S, Bayraktar C, Kaskalan E, et al. Concurrence of Left Maxillary Antrolith and Right-Sided Nasal Inverted Papilloma: Case Report. J Clin Med Case Reports. 2015;2(1): 4.

stroma (Figures 3 and 4). Left maxillary sinus was successfully managed by uncinectomy, maxillary sinusotomy, and inferior meatalantrostomy to remove the antrolith (Figure 5). There is no recurrence of IP at the end of first year, postoperatively (Figure 6).

\section{Discussion}

Clinical presentation of IP is most commonly a male subject with unilateral nasal obstruction and intermittent epistaxis who is 50-69 years old and it arises from the lateral nasal wall, particularly in the osteomeatal complex area of the middle meatus, and adjacent inferior and middle turbinates, and subsequently involves the contiguous paranasal sinuses, with the maxillary sinus [3]. Human papilloma virus (HPV), alterations in tumor suppressor gene $\mathrm{p} 53$, and chronic inflammation are suggested to be inducing and/or promoting agents in the pathogenesis of IP. The HPV serotypes, most commonly associated with IP, are 6,11,16, and 18 and serotypes 16 and 18 , similar to cervical cancer, are more commonly associated with malignancy $[5,9]$. Although the role of exposure to pollutants and toxins in the pathogenesis of IP remains controversial, there is growing evidence that these factors may be contributory. Exposure to diethylnitrosamine has been shown to cause IP in animal models [10]. A case control study on 47 patients with IP demonstrated a higher degree of exposure to smoke, dust, and aerosol among patients with IP [11]. Patients with IP most commonly have opacifications in adjacent

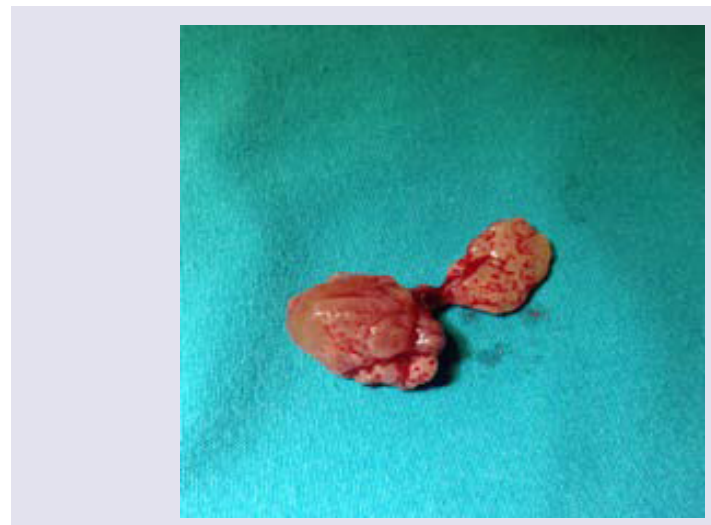

Figure 2: The en bloc resected material of the lesion from right maxillary sinus.

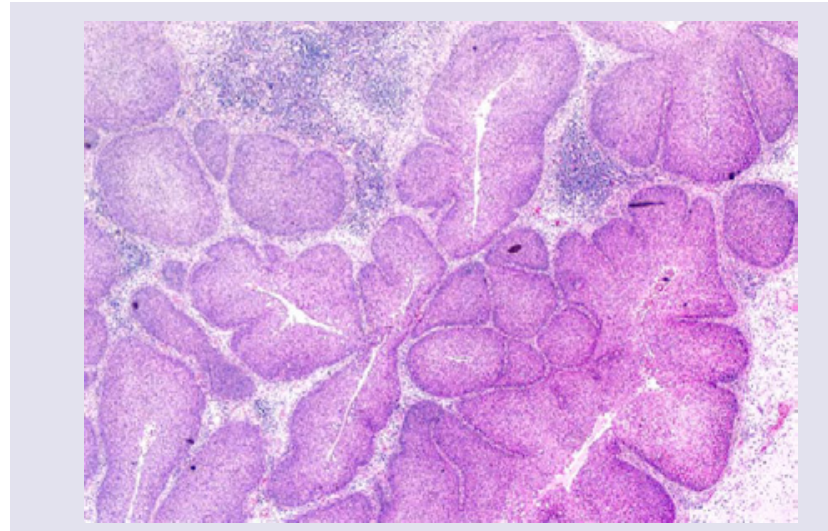

Figure 3: Digitiform proliferation of squamous epithelium into the underlying stroma (H\&E X 4).

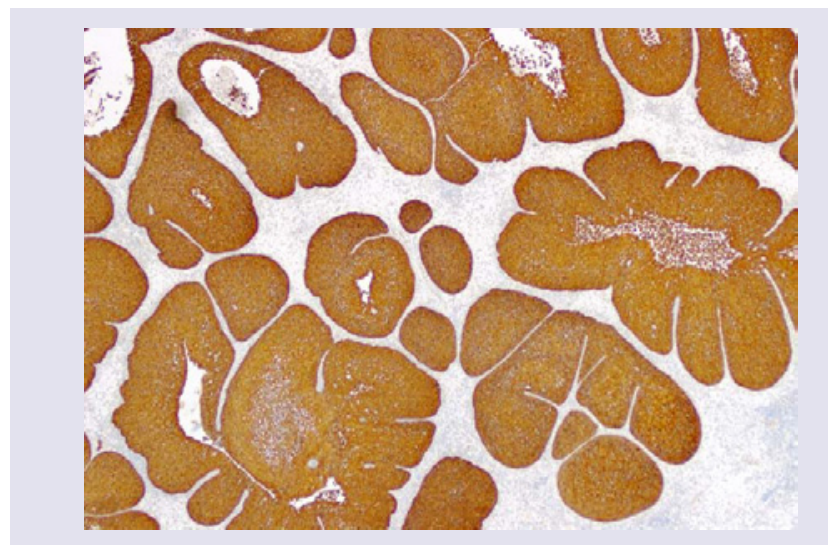

Figure 4: In pancytokeratin-stained tissue, digitiform proliferation of squamous epithelium into the underlying stroma (PAN-CK $X 4$ ).

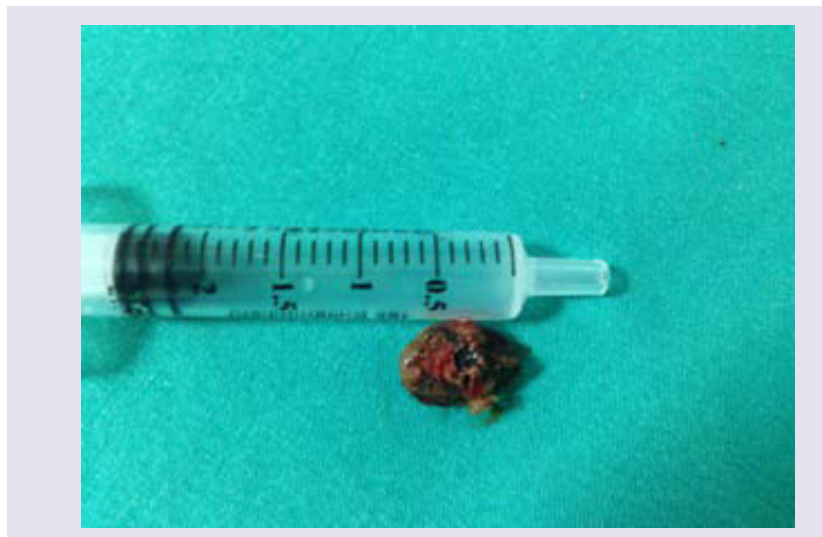

Figure 5: The solid mass taken out from left maxillary sinüs.

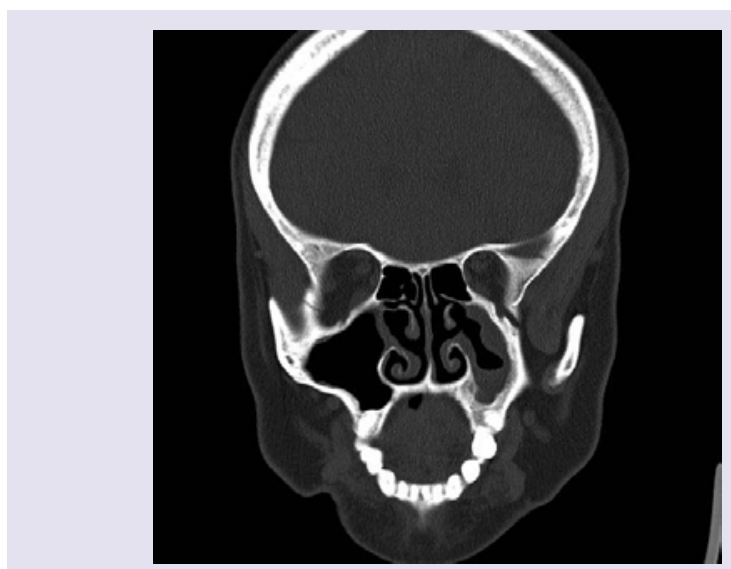

Figure 6: At postoperative $1^{\text {st }}$ year, mild mucosal thickening of left antrum and no recurrences of antrolith and inverted papilloma were observed.

maxillary antrum on plain film [12]. IP appears as a soft tissue density mass with some enhancement on CT. Focal hyperostosis which tends to occur at the site of tumour origin is sometimes detected on CT [13]. This finding is helpful not only in suggesting the diagnosis, but also to guide surgical planning, as the location of tumour origin determines the extent of surgery required. As IP enlarges bony resorption and destruction may occur and it may interfere with squamous cell 
carcinoma [14]. MRI often reveals a typical appearance named as convoluted cerebriform pattern on both $\mathrm{T} 2$ and contrast enhanced $\mathrm{T} 1$ weighted images. This sign is encountered in $50-100 \%$ of cases, and is uncommon in other sinonasaltumours [15]. Digitiform proliferation of squamous epithelium into the underlying stroma is the main characteristic microscopic finding of IPs. These mucosal lesions show invertion into underlying connective tissue unlike most papillomas of the body which display evertion [2]. Complete excision of these tumours is essential for adequate management and long-term control of them. Several surgical approaches include lateral rhinotomy, sublabial degloving approach, and simple endonasal techniques with visualization using a headlight or microscope. Due to high recurrence rate direct visualization or microscope use has fallen out of favor. Over the past 20 years transnasal endoscopic approach which provides the intraoperative endoscopic appearance and extent of the lesion, careful review of any questionable intraoperative margins as well as the final pathological specimen, and close follow-up with periodic nasal endoscopies, is now considered more onvenient [5,16,17]. The slow growth rate of IPs allows early detection of recurrences and even in-office excision of them [18-20]. Recent studies demonstrated that there are no significant differences in recurrence rates between open and endoscopic techniques when patients are appropriately selected for either technique [21]. In this case, we performed right uncinectomy, anterior ethmoidectomy, and maxillary sinusotomy and en bloc resection of IP with its antral and choanal parts. There was no residual tissue left in maxillary sinus during endoscopic evaluation at the end of surgery. Patient had no recurrence on CT and endoscopic examination at postoperative year 1 .

Antrolith is a mineralized mass that is encountered very rarely in the maxillary sinus formed by exogenous or endogenous origin. If $\mathrm{AL}$ is formed around body tissues, it is of endogenous origin including dried blood clots, pus, mucus secretions and fungi. If it originates outside the body, it is of exogenous origin including cotton, cellulose, paper, bead, button, vegetable/bean pieces [22]. They have been described in various names as antralrhinoliths, antral calculi, antroliths, sinoliths and antrorhinoliths [8,22]. The term "maxillary antrolith" was used first by Bowerman in 1969 to facilitate their classification and description of calculi found within the maxillary sinuses [23]. The maxillary sinus is lined by ciliated pseudostratified columnar epithelium which is required for secretion of mucous. Ostium opening, cilia, and secretion quality are necessary for its function and sinusitis is caused by blockage of that normal drainage. Chronic sinusitis, defined as recurrent episodes for more than 3 months, could result from untreated acute sinusitis. Thereby persistence of chronic sinusitis result in chronic inflammation associated with poor sinus drainage, deposition of salts and enzymatic activities of bacterial pathogens which are needed for the formation of an antrolith [23]. Pain, nasal stuffiness and obstruction, epistaxis, foul intraoral discharge, postnasal drip, tenderness over the involved sinus and, oro-antral fistula foul-smelling discharge, facial pain are the most common signs and symptoms of patients with $\mathrm{AL}$ in the literature [7,24,25]. Asymptomatic ALs encountered incidentally on routine radiographic imaging have also been reported $[26,27]$. Due to their various consistency, they may show homogenous and heterogenous density and sometimes alternating laminations of radiolucent and radiopaque material may be found. AL may be outlined as rugged or smooth and its shape may be round, oval or irregular. Antral mucosal swelling, fluid, and polyps sometimes accompany ALs [24]. CT is very useful in displaying a sinolith, detecting the type of calcification considering fungal or nonfungal origin of the sinolith and localizing it precisely in relation to adjacent tissues, specifically the medial orbital lamina and skull base bones [23]. Treatment of ALs includes surgical removal of stone together with appropriate tretment of coexisting sinus pathology. Most of ALs in the literature have been extracted via the outer approach $[23,28]$. Patient was subjected to left uncinectomy, maxillary sinusotomy, and inferior meatal antrostomy, then antrum was visualized with angled endoscopy. There was an irregular, black mass embedded in purulent secretion and it was extracted through dilated maxillary sinus ostium. There was no need for fenestration on anterior wall of maxillary sinus (Caldwell-Luc). Inferior meatal antrostomy was closed properly at the end of operation. Patient had no any pathology other than minimal mucosal thickening in left maxillary sinus on $\mathrm{CT}$ at postoperative year 1 .

In conclusion, MRI and CT, the most commonly used imaging modalities in paranasal sinus evaluation, may incidentally detect the pathologies other than the patient complains about. Herein, we present a case of a 65 -years old woman with complaints of right-sided nasal obstruction, epistaxis, and headache for the last 6 months. CT revealed moderate deviation of the nasal septum convexity to the left and the concurrence of left maxillary antrolith and right-sided nasal inverted papilloma which is the first case report in the literature. In the pathogenesis of both IP and $\mathrm{AL}$, chronic inflammation is the only shared pathway and patients with chronic inflammatory sinonasal disease should be managed as soon as possible to prevent complications like IP and AL.

\section{References}

1. Ward N (1854) A mirror of the practice of medicine and surgery in the hospitals of London. London Hosp Lancet 2: 480-482.

2. Ringert N (1938) Pathology of malignant tumors arising in the nasal and paranasal cavities and maxilla. Acta Otolaryngol (Stockh) 27: 31-42.

3. Wood JW, Casiano RR (2011) Inverted papillomas and benign nonneoplastic lesions of the nasal cavity. Am J Rhinol Allergy 26: 157-163.

4. Cody DT II, DeSanto LW (1998) Neoplasm of the nasal cavity. In Otolaryngology Head and Neck Surgery, Vol. 2, ed. 3. Cumming CW FJ, Harker LA, Krause CJ, et al. (Eds). St. Louis, MO: Mosby-Year Book, Inc., p: 883-901.

5. Caruana SM, Zwiebel N, Cocker R, McCormick SA, Eberle RC, et al. (1997) p53 Alteration and human papilloma virus in paranasal sinus cancer. Cancer 79: $1320-1328$

6. Evans J (1975) Maxillary antrolith: a case report. Br J Oral Surg 13: 73-77.

7. Nass Duce M, Talas DU, Ozer C, Yildiz A, Apaydin FD, et al. (2003) Antrolithiasis: a retrospective study. J Laryngol Otol 117: 637-640.

8. Manjaly G, Pahor AL (1994) Antral rhinolithiasis and tooth filling. Ear Nose Throat J 73: 676-679.

9. Furuta Y, Shinohara T, Sano K, Nagashima K, Inoue K, et al. (1991) Molecular pathological study of human papillomavirus infection in inverted papilloma and squamous cell carcinoma of the nasal cavities and paranasal sinuses. Laryngoscope 101: 79-85.

10. Herrold KM (1964) Epithelial papillomas of the nasal cavity; Experimenta induction in syrian hamsters. Arch Pathol 78: 189-195.

11. Dietmer T, Wiener C (1996) Is there an occupational etiology of inverted papilloma of the nose and sinuses. Acta Otolaryngol 116: 762-765. 
Citation: Karataş M, Sarıkaya Y, Doğan S, Bayraktar C, Kaskalan E, et al. Concurrence of Left Maxillary Antrolith and Right-Sided Nasal Inverted Papilloma: Case Report. J Clin Med Case Reports. 2015;2(1): 4.

12. Momose KJ, Weber AL, Goodman M, MacMillan AS Jr, Roberson GH (1980) Radiological aspects of inverted papilloma. Radiology 134: 73-79.

13. Lee DK, Chung SK, Dhong HJ, Kim HY, Kim HJ, et al. (2007) Focal hyperostosis on CT of sinonasal inverted papilloma as a predictor of tumor origin. AJNR Am J Neuroradiol 28: 618-621.

14. Yousem DM, Fellows DW, Kennedy DW, Bolger WE, Kashima H, et al. (1992) Inverted papilloma: evaluation with MR imaging. Radiology 185: 501-505.

15. Jeon TY, Kim HJ, Chung SK, Dhong HJ, Kim HY, et al. (2008) Sinonasa inverted papilloma: value of convoluted cerebriform pattern on MR imaging AJNR Am J Neuroradiol 29: 1556-1560.

16. Tufano RP, Thaler ER, Lanza DC, Goldberg AN, Kennedy DW (1999) Endoscopic management of sinonasal inverted papilloma. Am J Rhinol 13 423-426.

17. Lawson W, Patel ZM (2009) The evolution of management for inverted papilloma: an analysis of 200 cases. Otolaryngol Head Neck Surg 140: 330 335.

18. Kaza S, Capasso R, Casiano RR (2003) Endoscopic resection of inverted papilloma: University of Miami experience. Am J Rhinol 17: 185-190.

19. Levine HL (1990) The office diagnosis of nasal and sinus disorders using rigid nasal endoscopy. Otolarygol Head Neck Surg 102: 370-373.

20. Bolger WE, Kennedy DW (1992) Nasal endoscopy in the outpatient clinic.

\section{Otolaryngol Clin North Am 25: 791-802.}

21. Sautter NB, Cannady SB, Citardi MJ, Roh HJ, Batra PS (2007) Comparison of open versus endoscopic resection of inverted papilloma. Am J Rhinol 21: 320-323.

22. Karges MA, Eversole LR, Poindexter BJ Jr (1971) Antrolith: report of case and review of literature. J Oral Surg 29: 812-814.

23. Bowerman JE (1969) The maxillary antrolith. J Laryngol Otol 83: 873-882.

24. Crist RF, Johnson RL (1972) Antrolith: report of case. J Oral Surg 30: 694695.

25. Lo SH, Wu YY, Wang PC (2003) Maxillary Antrolith. Mid Taiwan J Med 8: 238- 241.

26. Cohen MA, Packota GV, Hall MJ, Steinberg J (1991) Large asymptomatic antrolith of the maxillary sinus. Report of a case. Oral Surg Oral Med Oral Pathol 71: 155-157.

27. Güneri P, Kaya A, ÇalışkanA (2005) Antroliths: survey of the literature and report of a case. Oral Surg Oral Med Oral Pathol Oral Radiol Endod 99: 517 521.

28. Wu CW, Tai CF, Wang LF, Tsai KB, Kuo WR (2005) Aspergillosis: a nidus of maxillary antrolith. Ant J Otolaryngol 26: 426-429. 